\title{
Role of Astroglial Hemichannels and Pannexons in Memory and Neurodegenerative Diseases
}

\author{
Juan A. Orellana ${ }^{1}$, Mauricio A. Retamal ${ }^{2}$, Rodrigo Moraga-Amaro ${ }^{3}$ and Jimmy Stehberg ${ }^{3 *}$ \\ ${ }^{1}$ Departamento de Neurología, Escuela de Medicina, Pontificia Universidad Católica de Chile, Santiago, Chile, ${ }^{2}$ Centro de \\ Fisiología Celular e Integrativa, Facultad de Medicina, Clínica Alemana Universidad del Desarrollo, Santiago, Chile, \\ ${ }^{3}$ Laboratorio de Neurobiología, Centro de Investigaciones Biomédicas, Universidad Andres Bello, Santiago, Chile
}

Under physiological conditions, astroglial hemichannels and pannexons allow the release of gliotransmitters from astrocytes. These gliotransmitters are critical in modulating synaptic transmission, plasticity and memory. However, recent evidence suggests that under pathological conditions, they may be central in the development of various neurodegenerative diseases. Here we review current literature on the role of astroglial hemichannels and pannexons in memory, stress and the development of neurodegenerative diseases, and propose that they are not only crucial for normal brain function, including memory, but also a potential target for the treatment of neurodegenerative diseases.

Keywords: connexin hemichannels, Cx hemichannels, connexin 43, pannexin, astrocytes, memory

\section{OPEN ACCESS}

Edited by:

Leif Hertz,

China Medical University, China

Reviewed by:

Luc Leybaert,

Ghent University, Belgium

Christian Naus,

University of British Columbia,

Canada

*Correspondence:

Jimmy Stehberg

istehberg@unab.cl

Received: 21 March 2016 Accepted: 06 July 2016

Published: 20 July 2016

Citation:

Orellana JA, Retamal MA Moraga-Amaro $R$ and Stehberg $J$ (2016) Role of Astroglial Hemichannels and Pannexons in Memory and Neurodegenerative

Diseases.

Front. Integr. Neurosci. 10:26. doi: 10.3389/fnint.2016.00026

\section{CONNEXIN HEMICHANNELS AND PANNEXIN CHANNELS}

In the 90's, a handful of studies demonstrated that molecular and ionic interchange between the intracellular and extracellular compartments can occur via a family of plasma membrane channels called hemichannels (Goodenough and Paul, 2003). Originally known as the building blocks of gap junction channels (GJC; Revel and Karnovsky, 1967), hemichannels release relevant quantities of autocrine and paracrine signaling molecules (e.g., ATP, glutamate, $\mathrm{NAD}^{+}$and $\mathrm{PGE}_{2}$ ) to the extracellular milieu, as well as the influx of small molecules and ions of up to $\sim 1.5 \mathrm{kDa}$ (e.g., glucose, cADPR and $\mathrm{Ca}^{2+}$ ) (Bruzzone et al., 2001; Stout et al., 2002; Ye et al., 2003; Cherian et al., 2005; Retamal et al., 2007; Song et al., 2011; Fiori et al., 2012). Each hemichannel or connexon is comprised of six connexins (Cxs). Cxs encompass a highly conserved protein family encoded by 21 genes in humans and 20 in mice, with orthologs in other vertebrate species (Eiberger et al., 2001; Abascal and Zardoya, 2013). Recently, another gene family encoding a set of three membrane proteins, termed pannexins (Panx 1-3), was identified (Panchin et al., 2000). Pannexins form single plasma membrane channels (Bruzzone et al., 2003) termed pannexons that participate in paracrine and autocrine signaling among cells (Bao et al., 2004; Locovei et al., 2006a).

Several studies show that hemichannels and pannexons play different physiological roles in the central nervous system (CNS), including ischemic tolerance (Orellana et al., 2014), establishment of adhesive interactions (Cotrina et al., 2008), fear memory consolidation (Stehberg et al., 2012), synaptic transmission (Prochnow et al., 2012; Chever et al., 2014), spontaneous electrical activity (Moore et al., 2014), glucose sensing (Orellana et al., 2012), chemoception (Reyes et al., 2014), blood-brain barrier (BBB) permeability (De Bock et al., 2011), redox sensing (Retamal et al., 2006) and neuronal migration (Liu et al., 2012). 


\section{HEMICHANNELS AND PANNEXONS IN ASTROCYTES}

Astrocytes play key roles in CNS function by providing nutrients (e.g., lactate; Pellerin, 2008) and redox molecules (Wilhelm and Hirrlinger, 2012), maintaining ionic balance (Kimelberg, 2005), $\mathrm{K}^{+}$clearance mediated by $\mathrm{Na}^{+} / \mathrm{K}^{+}$-ATPase (Sibille et al., 2014), glucose and lactate metabolism (Allaman et al., 2011), and neurotransmitter recycling of the two most abundant neurotransmitters in the brain: glutamate and GABA (Simard and Nedergaard, 2004). They also regulate cerebral microcirculation (Takano et al., 2006), and BBB permeability (Alvarez et al., 2013), among many other roles essential for normal brain function.

Additionally, it has been proposed that astrocytes actively participate in neuronal transmission and synaptic plasticity (Barres, 1989; Nedergaard, 1994; Parpura et al., 1994), via the release of molecules, known as gliotransmitters, into the synaptic cleft. In this context, Araque et al. (1998a,b) found that astrocytes surround synaptic buttons and release molecules into the synaptic cleft, modulating both preand post-synaptic activity. The term "tripartite synapse" was coined to describe synapses between neurons and astrocytes (Araque et al., 1999). Henceforth, several studies have proposed different pathways of gliotransmitter release from astrocytes, which appear to act in parallel and include $\mathrm{P} 2 \mathrm{X} 7$ receptors (Duan et al., 2003), pannexons (Iglesias et al., 2009), Cx43 hemichannels (Cotrina et al., 1998), transporters (Szatkowski et al., 1990), and vesicles (Parpura et al., 1994). For a summary of main gliotransmitter release mechanisms see Figure 1A.

Astrocytes show the highest level of $\mathrm{Cx}$ expression among brain cells, with $\mathrm{Cx} 43$ being the most abundantly expressed both in vitro and in vivo (Dermietzel et al., 1991; Naus et al., 1991). Astrocytes also express Cx30 (Nagy et al., 1999), Cx26 (Rash et al., 2001), and may also show Panx1 (Iglesias et al., 2009), at least after stress (Orellana et al., 2015). Cx43 and Panx1 form functional hemichannels and pannexons in astrocytes in vitro and ex vivo (Contreras et al., 2002; Iglesias et al., 2009; Orellana et al., 2011a).

Embedded in the "tripartite synapse", astrocytes express a plethora of receptors (reviewed in Moraga-Amaro et al., 2014) and respond locally to neurotransmitters through the above mentioned mechanisms of gliotransmitter release, including the activation of hemichannels and pannexons (Malarkey and Parpura, 2008). Indeed, several gliotransmitters such as Dserine, glutamate, ATP and lactate have been reported to be released via astrocytic hemichannels (Stout et al., 2002; Ye et al., 2003; Karagiannis et al., 2015) or pannexons (Iglesias et al., 2009; Pan et al., 2015) in vitro. This gliotransmitter release has been proposed to be necessary for different CNS functions in vivo (Orellana and Stehberg, 2014; Montero and Orellana, 2015). Other in vitro studies have reported $\mathrm{Cx} 43$ hemichannels to be permeable to $\mathrm{NAD}^{+}$(Bruzzone et al., 2001), glucose (Retamal et al., 2007), taurine (Stridh et al., 2008), and $\mathrm{Ca}^{2+}$ (Schalper et al., 2010). Moreover, given that GJCs have been shown to allow for the passage of small peptides with a molecular weight of up to $1.8 \mathrm{kDa}$ (Neijssen et al., 2005) and short interfering RNAs (Valiunas et al., 2005), it is possible that hemichannels may also allow the passage of such molecules, hypothesis that has not been tested so far.

Most early studies on hemichannels were performed in vitro, and suggested that $\mathrm{Cx} 43$ hemichannels have a low open probability in physiological conditions, requiring depolarized membrane potentials as high as $+60 \mathrm{mV}$. Given that astrocytes are considered non-excitable cells in terms of membrane potential, their opening under physiological conditions was considered virtually impossible. However, later studies showed hemichannel opening at negative membrane potentials as measured by hemichannel-mediated dye uptake and ionic currents (Contreras et al., 2003; Retamal et al., 2007).

Recent in vitro studies have shown that astroglial $\mathrm{Cx} 43$ hemichannel activity changes in response to general anesthetics (Liu et al., 2016) antidepressants (Jeanson et al., 2015) and modafinil (Duchêne et al., 2016), suggesting that they may also be drug targets.

\section{EVIDENCE FOR ASTROGLIAL HEMICHANNEL FUNCTION IN VIVO}

The evidence of a role for astroglial hemichannels and pannexons in vivo in astroglial physiology and CNS function is much more limited, and is only now beginning to emerge. A recent study reported that astroglial $\mathrm{Cx} 43$ hemichannels are active in hippocampal slices during basal conditions and that astroglial Cx43 hemichannel-dependent release of ATP increases basal excitatory (glutamatergic) synaptic transmission through P2 receptors (Chever et al., 2014). Similar results were reported in neurons that project to the vagal nerve (Retamal et al., 2014).

Astroglial Cx43 hemichannel opening may also contribute to neuronal oscillations. Roux et al. (2015) reported that astroglial Cx43 hemichannel opening in olfactory bulb slices increases the amplitude of slow oscillations in mitral cells, affecting their firing rate. Hemichannel activity is also necessary for maintaining spontaneous activity in the cortex during development (Moore et al., 2014). It remains unknown whether hemichannels are still relevant for spontaneous activity in the adult cortex.

Yet another example of the role of astroglial hemichannels in CNS function measured in vivo can be found in the retrotrapezoid nucleus, in which the firing rate of $\mathrm{CO}_{2} / \mathrm{H}^{+}$. sensitive neurons acting as chemoreceptors (Wenker et al., 2012; Reyes et al., 2014) is modulated by ATP release from astrocytes via Cx26 hemichannels (Huckstepp et al., 2010).

In a recent study by Orellana et al. (2015), we reported from ex-vivo hippocampal slices that acute $2 \mathrm{~h}$ restraint stress in mice induces opening of astroglial $\mathrm{Cx} 43$ hemichannels, while chronic 10-day immobilization stress-a model used to induce depression in rodents-leads to increased opening of Cx43 hemichannels, and recruitment of astroglial Panx1 channels. This increase in hemichannel activity correlated with an increase in glutamate and ATP release, being dependent on 


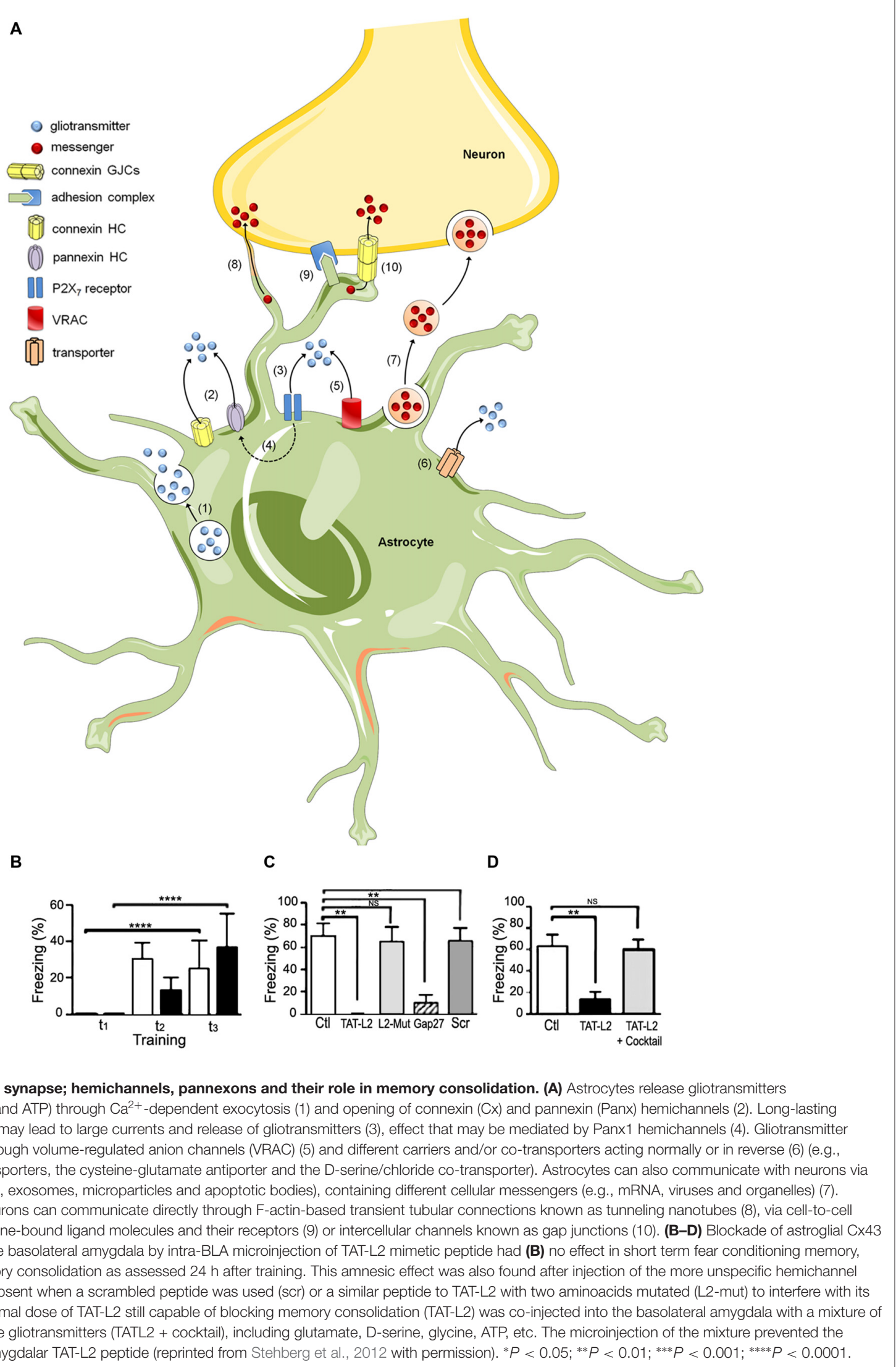

FIGURE 1 | The tripartite synapse; hemichannels, pannexons and their role in memory consolidation. (A) Astrocytes release gliotransmitters (e.g., glutamate, D-serine and ATP) through $\mathrm{Ca}^{2+}$-dependent exocytosis (1) and opening of connexin (Cx) and pannexin (Panx) hemichannels (2). Long-lasting activation of P2X7 by ATP may lead to large currents and release of gliotransmitters (3), effect that may be mediated by Panx 1 hemichannels (4). Gliotransmitter release may also occur through volume-regulated anion channels (VRAC) (5) and different carriers and/or co-transporters acting normally or in reverse (6) (e.g., excitatory amino-acid transporters, the cysteine-glutamate antiporter and the D-serine/chloride co-transporter). Astrocytes can also communicate with neurons via the release of vesicles (e.g., exosomes, microparticles and apoptotic bodies), containing different cellular messengers (e.g., mRNA, viruses and organelles) (7). Adjacent glial cells and neurons can communicate directly through F-actin-based transient tubular connections known as tunneling nanotubes (8), via cell-to-cell contacts between membrane-bound ligand molecules and their receptors (9) or intercellular channels known as gap junctions (10). (B-D) Blockade of astroglial Cx43 hemichannel opening in the basolateral amygdala by intra-BLA microinjection of TAT-L2 mimetic peptide had (B) no effect in short term fear conditioning memory, (C) but blocked fear memory consolidation as assessed $24 \mathrm{~h}$ after training. This amnesic effect was also found after injection of the more unspecific hemichannel blocker GAP27, but was absent when a scrambled peptide was used (scr) or a similar peptide to TAT-L2 with two aminoacids mutated (L2-mut) to interfere with its affinity for CX43. (D) A minimal dose of TAT-L2 still capable of blocking memory consolidation (TAT-L2) was co-injected into the basolateral amygdala with a mixture of TAT-L2 and various putative gliotransmitters (TATL2 + cocktail), including glutamate, D-serine, glycine, ATP, etc. The microinjection of the mixture prevented the amnesic effects of intra-amygdalar TAT-L2 peptide (reprinted from Stehberg et al., 2012 with permission). ${ }^{*} P<0.05 ;{ }^{* *} P<0.01 ;{ }^{* * *} P<0.001 ;{ }^{* * * *} P<0.0001$. 
glutamatergic $\mathrm{N}$-methyl-D-aspartate (NMDA) and purinergic receptor signaling (Orellana et al., 2015). Moreover, Garré et al. (2016) showed that FGF-1 promotes inflammatory responses in acute spinal cord slices by a mechanism that involves release of ATP through Panxl channels. Finally, in another study we shall discuss in more detail later, we showed that $\mathrm{Cx} 43$ hemichannels are necessary for fear memory consolidation in the basolateral amygdala (Stehberg et al., 2012).

As can be deduced from the above paragraph, in vivo evidence supporting a role for hemichannels and pannexons in CNS function is very recent, still limited in number but growing fast.

Astroglial hemichannels open in response to local increments in intracellular $\mathrm{Ca}^{2+}$. Astrocytes express receptors and respond to most neurotransmitters known to be relevant for memory (for a review see Moraga-Amaro et al., 2014) via fast and local $\mathrm{Ca}^{2+}$ oscillations or inter-astrocytic $\mathrm{Ca}^{2+}$ waves at speeds matching neuronal activity (Winship et al., 2007). Thus, astroglial activation may trigger the opening of hemichannels or pannexons and the concomitant release of D-serine, glutamate, ATP and lactate, among various other gliotransmitters (Orellana and Stehberg, 2014). D-serine is a co-agonist of NMDA receptors critical for synaptic plasticity (Henneberger et al., 2010). Glutamate is the main excitatory neurotransmitter in the CNS and lactate is critical for brain metabolism and acts as a neurotransmitter activating NMDA receptors (Yang et al., 2014), all of which are critical for synaptic plasticity and memory. ATP mediates propagation of inter-astrocytic $\mathrm{Ca}^{2+}$ waves by activating astroglial purinergic receptors, whereas its conversion into adenosine may activate neuronal purinergic receptors (Zhang et al., 2003). As a consequence, it is likely that these functions are mediated by astroglial hemichannels and pannexons, but direct in vivo evidence is still lacking.

\section{ASTROGLIAL HEMICHANNELS AND PANNEXONS IN MEMORY}

As mentioned earlier, astroglial hemichannels and pannexons allow for the delivery of a wide variety of gliotransmitters to the extracellular milieu. However, the role of these channels in brain function under physiological conditions, and particularly in memory, has only recently begun to be elucidated. In 2012, we demonstrated that blockade of $\mathrm{Cx} 43$ hemichannels at the basolateral amygdala in vivo, using a mimetic peptide known as TAT-L2, had no effects on short term memory (Figure 1B), yet blocked memory consolidation, inducing amnesia for auditory fear conditioning $24 \mathrm{~h}$ after training (Figure 1C). Interestingly, the amnesic effect of the peptide was prevented by co-injecting it together with a cocktail of gliotransmitters, including glutamate, D-serine, glycine, lactate, ATP and glutamine (Figure 1D; Stehberg et al., 2012). This indicates that the opening of Cx43 hemichannels permits the release of gliotransmitters necessary for memory consolidation, but we were not able to identify the gliotransmitter or combination of gliotransmitters that is critical for memory. In this respect, a previous study by
Henneberger et al. (2010) reported that preventing calcium oscillations in astrocytes averted long-term potentiation (LTP, a model of synaptic plasticity associated to memory) in hippocampal slices. This effect was reverted by exogenous administration of D-serine to the preparation (Henneberger et al., 2010). D-serine is a co-agonist of glutamate NMDA receptors which is secreted by astrocytes and is critical for LTP induction (Henneberger et al., 2010; Kang et al., 2013). There is currently no direct evidence that $\mathrm{D}$-serine can be released via $\mathrm{Cx} 43$ hemichannels, but it is possible, as astroglial pannexons have been reported to release D-serine in vitro (Pan et al., 2015).

Genetic studies affecting $\mathrm{Cx}$ expression have had limited value in deciphering the role of hemichannels, as current genetic approaches affect the expression of both hemichannels and GJCs and do not allow for the distinction of the effects of either. Double knockout mice for both $\mathrm{Cx} 43$ and $\mathrm{Cx} 30$, the two main Cxs expressed in astrocytes, show enhanced synaptic transmission, attenuated LTP and increased long-term depression (LTD) in hippocampal CA1 pyramidal cells (Pannasch et al., 2011), which are critical for memory formation.

It is still debated whether Pannexons form GJCs in vitro (Sosinsky et al., 2011; Sahu et al., 2014). Unlike Cx43, which is expressed mainly in astrocytes (also reported in microglia, radial glia and neural progenitors; Nadarajah et al., 1997; Boucher and Bennett, 2003), Panx1 is expressed in both astrocytes and neurons (Zoidl et al., 2007; Iglesias et al., 2009; Santiago et al., 2011). Thus, Panx1 deficiency by genetic knockout or pharmacological approaches cannot distinguish neuronal from astroglial pannexons. Both pharmacological blockade and genetic deficiency of Panxl channels induce increased excitability, enhanced LTP, reduced LTD and impairments in object recognition and spatial memory (Prochnow et al., 2012; Ardiles et al., 2014). This evidence depicts a clear role for Panx1 in synaptic plasticity and memory, regardless of whether they originate from astrocytes, neurons, or both.

\section{HEMICHANNELS AND PANNEXONS IN PSYCHIATRIC DISORDERS ASSOCIATED WITH COGNITIVE DYSFUNCTION}

Thus far no study has reported a direct role for astroglial hemichannels in psychiatric disorders that can be associated with memory. However, in Orellana et al. (2015), we showed that astroglial $\mathrm{Cx} 43$ hemichannel activity in the hippocampus is increased after acute restraint stress in mice, effects that were associated with a Cx43-dependent increase in extracellular levels of glutamate and ATP (Orellana et al., 2015). Interestingly, when mice underwent a protocol of chronic restraint stress commonly used to induce depressive-like symptoms in mice, an even greater increase in $\mathrm{Cx} 43$ hemichannel activity was induced, together with Panx1 channel opening, with the concomitant $\mathrm{Cx} 43$ - and Panx1-dependent release of glutamate and ATP (Orellana et al., 2015). This study was followed by the work of Quesseveur et al. (2015), reporting that knockdown of Cx43 in mice induced anxiolytic- and antidepressant-like effects and an increase in 


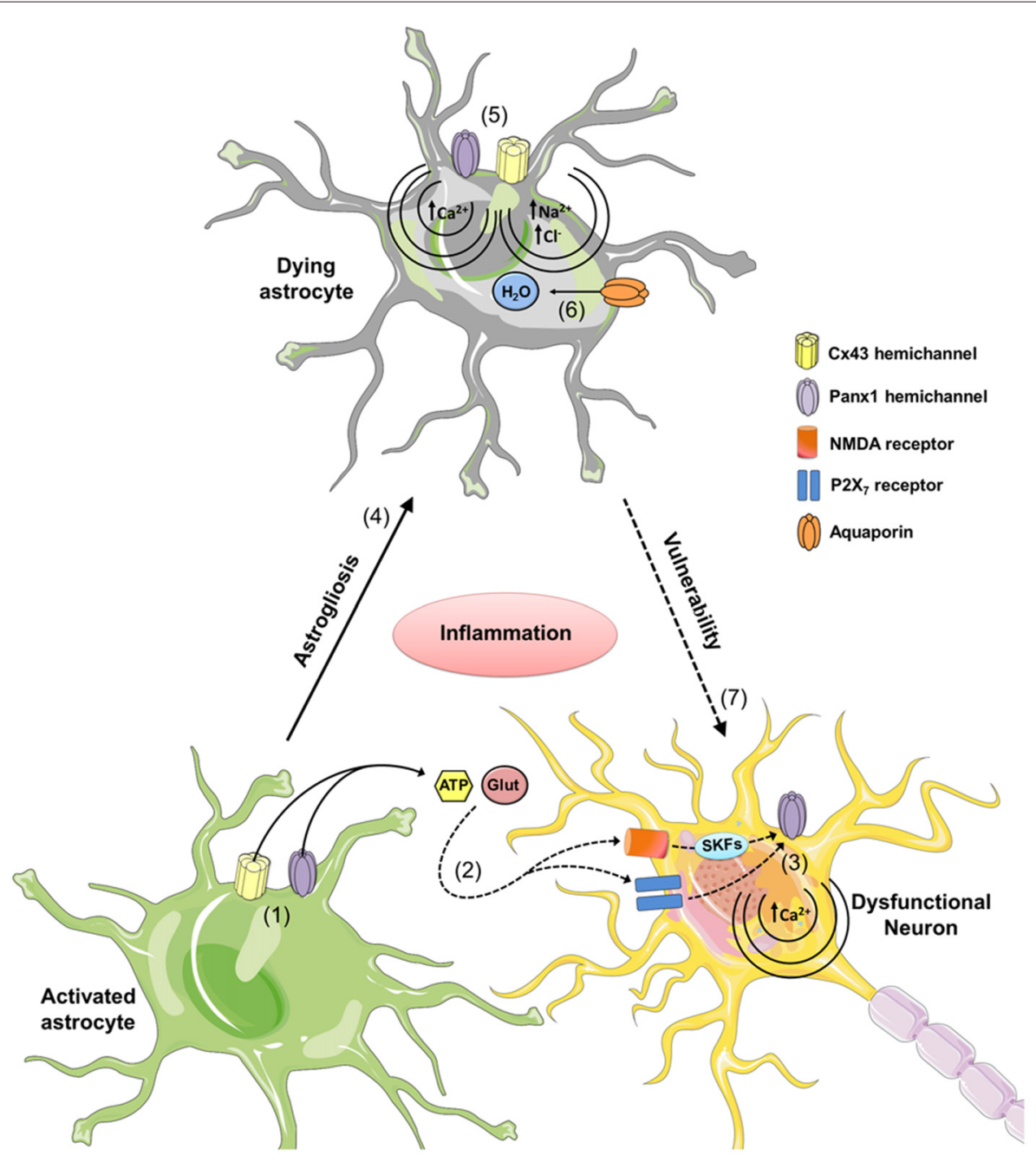

FIGURE 2 | The role of astrocytic hemichannels and pannexons during neurodegeneration. During the early stages of various neurodegenerative diseases, increased inflammation opens astrocytic Cx43 hemichannels and Panx1 channels (1). This results in the release of the gliotransmitters ATP and glutamate, and increases activation of neuronal NMDA and P2X7 receptors (2). It is hypothesized that NMDA and P2X7 receptor activation increases the opening of neuronal Panx1 channels through phosphorylation of Panx1 by Src family kinases (SFKs) and direct protein-to-protein interactions, respectively (3). These P2X7-related protein interactions could affect intracellular $\mathrm{Ca}^{2+}$ homeostasis resulting in cell death. Uncontrolled activation of astrocytes may result in reactive astrogliosis and further cell death by a mechanism related to the opening of connexons and pannexons (4). In particular, dysregulated opening of $\mathrm{Cx} 43$ and Panx 1 channels could elicit cellular damage by different mechanisms. At one end of the connexon, the entry of $\mathrm{Ca}^{2+}$ via the $\mathrm{Cx} 43$ hemichannels or Panx $1 \mathrm{channels}$ The added Ca ${ }^{2+}$ activates phospholipase $\mathrm{A}_{2}$, thus generating arachidonic acid and activating the cyclooxygenase and lipoxygenase pathways, resulting in increased free radicals, lipid peroxidation and plasma membrane damage (5). At the other end of the connexon, $\mathrm{Na}^{+}$and $\mathrm{Cl}^{-}$entry via $\mathrm{Cx} 43$ hemichannels or Panx1 channels may trigger cellular swelling due to an increased influx of $\mathrm{H}_{2} \mathrm{O}$ via aquaporins (6). Finally, given that astrocytes provide support to neurons, astroglial cell damage associated with hemichannel/pannexon opening could indirectly increase neuronal susceptibility and vulnerability due to the homeostatic imbalance occurring during neurodegeneration.

freezing in the fear-conditioning paradigm. Interestingly, it was found that chronic corticosterone administration (another model used to induce depression in rodents), caused an increase in the expression of phosphorylated $\mathrm{Cx} 43$ in the hippocampus, effect that was reversed by successful antidepressant treatment (Quesseveur et al., 2015). This is further supported by a recent study showing that antidepressants affect astroglial Cx43 GJC and hemichannel activity (Jeanson et al., 2015). The above findings suggest that hippocampal Cx43 hemichannel activity may be important in stress responses and for the pathophysiology of depression. How they may contribute to arousal-induced memory enhancements, post-traumatic stress disorder or depression-associated cognitive impairments are exciting questions that may be answered in the near future.

\section{HEMICHANNELS AND PANNEXONS IN NEURODEGENERATIVE DISEASES}

Many neurodegenerative diseases are characterized by destruction of memory related areas, including the hippocampus, 
prefrontal cortex, mediotemporal lobe, nucleus basalis, basal ganglia, etc. (for reviews on areas involved in memory see Packard and Knowlton, 2002; Jeong et al., 2015). For example, in Alzheimer's disease (AD), extensive damage to the hippocampus and cortical areas has been associated with cognitive deficits (reviewed in Pini et al., 2016). Likewise, in frontotemporal dementia, damage to frontal and anterior temporal lobes was also associated with cognitive deficits (Finger, 2016), while in Parkinson's disease (PD), damage to basal ganglia and frontal connectivity has also been correlated with cognitive deficits (Zgaljardic et al., 2003).

Various studies have linked dysregulation of hemichannel and pannexon permeability and expression, with the progression of different neurodegenerative diseases (Orellana and Stehberg, 2014; Penuela et al., 2014). However, the mechanisms by which astroglial hemichannels and pannexons contribute to neuronal damage remain elusive. It is possible that enhanced reactive astrogliosis evoked by neuroinflammation may alter different astroglial functions necessary for proper astrocyte-to-neuron crosstalk and neuronal survival, including synaptic gliotransmission, $\mathrm{Ca}^{2+}$ and $\mathrm{NO}$ signaling, as well as antioxidant and inflammatory responses. Hemichannels and pannexons are both affected by multiple inflammatory mediators released by reactive astrocytes and microglia (e.g., cytokines, NO and ROS; Retamal et al., 2007; Abudara et al., 2015). Inflammatory conditions could increase astroglial hemichannel/pannexon opening, leading to an uncontrolled influx of potentially toxic agents, as is the case of $\mathrm{Ca}^{2+}$. Because hemichannels are permeable to $\mathrm{Ca}^{2+}$ (De Bock et al., 2012; Fiori et al., 2012), and their opening is controlled by intracellular $\mathrm{Ca}^{2+}$ (De Bock et al., 2012), it is possible that overactivation of hemichannels/pannexons results in intracellular $\mathrm{Ca}^{2+}$ overload and the subsequent impairment of vital functions for astroglial survival; including energy metabolism, $\mathrm{Ca}^{2+}$ handling, osmotic regulation and antioxidant defense. Consistent with this notion, hemichannel and pannexon activity has been linked to an alteration in $\mathrm{Ca}^{2+}$ dynamics and cell death in reactive astrocytes (Orellana et al., 2010; Abudara et al., 2015; Rovegno et al., 2015). In addition, osmotic and ionic imbalances induced by uncontrolled influx of $\mathrm{Na}^{+}$and $\mathrm{Cl}^{-}$through these channels could result in further cell swelling and plasma membrane breakdown. Given that astrocytes provide metabolic, synaptic and trophic support to neurons and maintain the extracellular microenvironment, astroglial cell damage or dysfunction associated with hemichannel and pannexon opening could increase neuronal susceptibility to different pathological conditions (Contreras et al., 2004; Orellana et al., 2009).

Alternatively, uncontrolled opening of hemichannels and pannexons induced by inflammatory conditions may trigger excessive release of molecules at toxic levels, such as glutamate and ATP. Consistent with this idea, astrocytes stimulated with amlyloid- $\beta$ (A $\beta)$ peptide exhibit increased Cx43 hemichannel-dependent release of glutamate and ATP, which are toxic for hippocampal and cortical neurons
(Orellana et al., 2011a). Similarly, a follow-up work showed that astrocytes pre-treated with conditioned media from $A \beta$ peptide-stimulated microglia release neurotoxic amounts of glutamate and ATP via $\mathrm{Cx} 43$ hemichannels when subjected to hypoxia in high glucose conditions (Orellana et al., 2011b). Interestingly, their release reduced neuronal survival via activation of neuronal NMDA/P2X7 receptors and Panx1 channels in neurons (Orellana et al., 2011a,b). Neurons express functional hemichannels formed by Cx36 and pannexons formed by Panx1 (Thompson et al., 2006; Zappalà et al., 2006), and the opening of Panx1 channels could occur via protein-protein interactions with activated P2X7 receptors (Iglesias et al., 2008), through increases in intracellular $\mathrm{Ca}^{2+}$ or phosphorylation triggered by activation of P2Y (Locovei et al., 2006b) or NMDA receptors (Weilinger et al., 2012). For a scheme of proposed roles for hemichannels and pannexons in neurodegeneration, see

Figure 2.

\section{CONCLUDING REMARKS}

Exciting research on astrocytes and particularly on astroglial hemichannels and pannexons characterizes the last few years. Although hemichannels and pannexons initially appeared to be one of the many cellular mechanisms used by astrocytes to share their gliotransmitters, accumulating evidence indicates that astroglial hemichannels play a key role in brain function under physiological conditions, and in pathology. In normal conditions astroglial hemichannels and pannexons are important for memory consolidation, stress response, and possibly even for the pathophysiology of depression. Given their role in NMDA-dependent plasticity, they may also prove to be relevant in depression-associated memory impairments. Yet in pathological conditions, they appear to have a central role in the development of neurodegenerative diseases. Although many questions remain unanswered regarding their role in memory and in cognitive dysfunction, it is clear that astroglial hemichannels and pannexons play essential roles, in sickness and in health, until death do us part.

\section{AUTHOR CONTRIBUTIONS}

Review was divided into equal parts, which were combined and edited by JS. JAO made Figure 2; JS and JAO made Figure 1. All authors listed, have made substantial, direct and intellectual contribution to the work, and approved it for publication.

\section{FUNDING}

This work was supported by grants FONDECYT 11121133 (JAO), 1160710 (JAO), 1120214 (MAR) and 1160986 (JS); UNAB DI-603-14/N (JS), CORFO 14IDL2-30195 (JS); CAEN from the ISFN (JAO), and CONICYT ACT 1104 (MAR) and ACT 1411 (JAO). We wish to thank Kathleen McBennett for her contributions. 


\section{REFERENCES}

Abascal, F., and Zardoya, R. (2013). Evolutionary analyses of gap junction protein families. Biochim. Biophys. Acta 1828, 4-14. doi: 10.1016/j.bbamem.2012. 02.007

Abudara, V., Roux, L., Dallérac, G., Matias, I., Dulong, J., Mothet, J. P., et al. (2015). Activated microglia impairs neuroglial interaction by opening Cx43 hemichannels in hippocampal astrocytes. Glia 63, 795-811. doi: 10.1002/glia. 22785

Allaman, I., Bélanger, M., and Magistretti, P. J. (2011). Astrocyte-neuron metabolic relationships: for better and for worse. Trends Neurosci. 34, 76-87. doi: 10 . 1016/j.tins.2010.12.001

Alvarez, J. I., Katayama, T., and Prat, A. (2013). Glial influence on the blood brain barrier. Glia 61, 1939-1958. doi: 10.1002/glia.22575

Araque, A., Parpura, V., Sanzgiri, R. P., and Haydon, P. G. (1998a). Glutamatedependent astrocyte modulation of synaptic transmission between cultured hippocampal neurons. Eur. J. Neurosci. 10, 2129-2142. doi: 10.1046/j.14609568.1998.00221.x

Araque, A., Sanzgiri, R. P., Parpura, V., and Haydon, P. G. (1998b). Calcium elevation in astrocytes causes an NMDA receptor-dependent increase in the frequency of miniature synaptic currents in cultured hippocampal neurons. J. Neurosci. 18, 6822-6829.

Araque, A., Parpura, V., Sanzgiri, R. P., and Haydon, P. G. (1999). Tripartite synapses: glia, the unacknowledged partner. Trends Neurosci. 22, 208-215. doi: 10.1016/s0166-2236(98)01349-6

Ardiles, A. O., Flores-Muñoz, C., Toro-Ayala, G., Cárdenas, A. M., Palacios, A. G., Muñoz, P., et al. (2014). Pannexin 1 regulates bidirectional hippocampal synaptic plasticity in adult mice. Front. Cell. Neurosci. 8:326. doi: 10.3389/fncel. 2014.00326

Bao, L., Locovei, S., and Dahl, G. (2004). Pannexin membrane channels are mechanosensitive conduits for ATP. FEBS Lett. 572, 65-68. doi: 10.1016/j. febslet.2004.07.009

Barres, B. A. (1989). Neuronal-glial interactions. A new form of transmission? Nature 339, 343-344. doi: 10.1038/339343a0

Boucher, S., and Bennett, S. A. (2003). Differential connexin expression, gap junction intercellular coupling and hemichannel formation in NT2/D1 human neural progenitors and terminally differentiated hNT neurons. J. Neurosci. Res. 72, 393-404. doi: 10.1002/jnr.10575

Bruzzone, S., Guida, L., Zocchi, E., Franco, L., and De Flora, A. (2001). Connexin 43 hemi channels mediate $\mathrm{Ca}^{2+}$-regulated transmembrane $\mathrm{NAD}^{+}$fluxes in intact cells. FASEB J. 15, 10-12. doi: 10.1096/fj.00-0566fje

Bruzzone, R., Hormuzdi, S. G., Barbe, M. T., Herb, A., and Monyer, H. (2003). Pannexins, a family of gap junction proteins expressed in brain. Proc. Natl. Acad. Sci. U S A 100, 13644-13649. doi: 10.1073/pnas.2233464100

Cherian, P. P., Siller-Jackson, A. J., Gu, S., Wang, X., Bonewald, L. F., Sprague, E., et al. (2005). Mechanical strain opens connexin 43 hemichannels in osteocytes: a novel mechanism for the release of prostaglandin. Mol. Biol. Cell 16, 3100-3106. doi: 10.1091/mbc.e04-10-0912

Chever, O., Lee, C. Y., and Rouach, N. (2014). Astroglial connexin43 hemichannels tune basal excitatory synaptic transmission. J. Neurosci. 34, 11228-11232. doi: 10.1523/JNEUROSCI.0015-14.2014

Contreras, J. E., Sáez, J. C., Bukauskas, F. F., and Bennett, M. V. (2003). Gating and regulation of connexin 43 (Cx43) hemichannels. Proc. Natl. Acad. Sci. U S A 100, 11388-11393. doi: 10.1073/pnas.1434298100

Contreras, J. E., Sánchez, H. A., Eugenin, E. A., Speidel, D., Theis, M., Willecke, K., et al. (2002). Metabolic inhibition induces opening of unapposed connexin 43 gap junction hemichannels and reduces gap junctional communication in cortical astrocytes in culture. Proc. Natl. Acad. Sci. U S A 99, 495-500. doi: 10. 1073/pnas.012589799

Contreras, J. E., Sánchez, H. A., Véliz, L. P., Bukauskas, F. F., Bennett, M. V., and Sáez, J. C. (2004). Role of connexin-based gap junction channels and hemichannels in ischemia-induced cell death in nervous tissue. Brain Res. Brain Res. Rev. 47, 290-303. doi: 10.1016/j.brainresrev.2004.08.002

Cotrina, M. L., Lin, J. H., Alves-Rodrigues, A., Liu, S., Li, J., Azmi-Ghadimi, H., et al. (1998). Connexins regulate calcium signaling by controlling ATP release. Proc. Natl. Acad. Sci. U S A 95, 15735-15740. doi: 10.1073/pnas.95.26.15735

Cotrina, M. L., Lin, J. H., and Nedergaard, M. (2008). Adhesive properties of connexin hemichannels. Glia 56, 1791-1798. doi: 10.1002/glia.20728
De Bock, M., Culot, M., Wang, N., Bol, M., Decrock, E., De Vuyst, E., et al. (2011) Connexin channels provide a target to manipulate brain endothelial calcium dynamics and blood-brain barrier permeability. J. Cereb. Blood Flow Metab. 31, 1942-1957. doi: 10.1038/jcbfm.2011.86

De Bock, M., Wang, N., Bol, M., Decrock, E., Ponsaerts, R., Bultynck, G., et al. (2012). Connexin 43 hemichannels contribute to cytoplasmic $\mathrm{Ca}^{2+}$ oscillations by providing a bimodal $\mathrm{Ca}^{2+}$-dependent $\mathrm{Ca}^{2+}$ entry pathway. J. Biol. Chem. 287, 12250-12266. doi: 10.1074/jbc.M111.299610

Dermietzel, R., Hertberg, E. L., Kessler, J. A., and Spray, D. C. (1991). Gap junctions between cultured astrocytes: immunocytochemical, molecular and electrophysiological analysis. J. Neurosci. 11, 1421-1432.

Duan, S., Anderson, C. M., Keung, E. C., Chen, Y., Chen, Y., and Swanson, R. A. (2003). P2X7 receptor-mediated release of excitatory amino acids from astrocytes. J. Neurosci. 23, 1320-1328.

Duchêne, A., Perier, M., Zhao, Y., Liu, X., Thomasson, J., Chauveau, F., et al. (2016). Impact of astroglial connexins on modafinil pharmacological properties. Sleep 39, 1283-1292. doi: 10.5665/sleep.5854

Eiberger, J., Degen, J., Romualdi, A., Deutsch, U., Willecke, K., and Söhl, G. (2001) Connexin genes in the mouse and human genome. Cell Commun. Adhes. 8 163-165. doi: 10.3109/15419060109080717

Finger, E. C. (2016). Frontotemporal dementias. Continuum (Minneap Minn) 22, 464-489. doi: 10.1212/CON.0000000000000300

Fiori, M. C., Figueroa, V., Zoghbi, M. E., Saéz, J. C., Reuss, L., and Altenberg, G. A. (2012). Permeation of calcium through purified connexin 26 hemichannels. J. Biol. Chem. 287, 40826-40834. doi: 10.1074/jbc.M112.383281

Garré, J. M., Yang, G., Bukauskas, F. F., and Bennett, M. V. (2016). FGF-1 triggers pannexin-1 hemichannel opening in spinal astrocytes of rodents and promotes inflammatory responses in acute spinal cord slices. J. Neurosci. 36, 4785-4801. doi: 10.1523/JNEUROSCI.4195-15.2016

Goodenough, D. A., and Paul, D. L. (2003). Beyond the gap: functions of unpaired connexon channels. Nat. Rev. Mol. Cell Biol. 4, 285-294. doi: 10.1038/ nrm1072

Henneberger, C., Papouin, T., Oliet, S. H., and Rusakov, D. A. (2010). Longterm potentiation depends on release of D-serine from astrocytes. Nature 463, 232-236. doi: 10.1038/nature08673

Huckstepp, R. T., Id Bihi, R., Eason, R., Spyer, K. M., Dicke, N., Willecke, K., et al. (2010). Connexin hemichannel-mediated CO2-dependent release of ATP in the medulla oblongata contributes to central respiratory chemosensitivity. J. Physiol. 588, 3901-3920. doi: 10.1113/jphysiol.2010.192088

Iglesias, R., Dahl, G., Qiu, F., Spray, D. C., and Scemes, E. (2009). Pannexin 1: the molecular substrate of astrocyte "hemichannels". J. Neurosci. 29, 7092-7097. doi: 10.1523/JNEUROSCI.6062-08.2009

Iglesias, R., Locovei, S., Roque, A., Alberto, A. P., Dahl, G., Spray, D. C., et al. (2008). P2X7 receptor-Pannexin1 complex: pharmacology and signaling. Am J. Physiol. Cell Physiol. 295, C752-C760. doi: 10.1152/ajpcell.00228.2008

Jeanson, T., Pondaven, A., Ezan, P., Mouthon, F., Charveriat, M., and Giaume, C. (2015). Antidepressants impact connexin 43 channel functions in astrocytes. Front. Cell. Neurosci. 9:495. doi: 10.3389/fncel.2015. 00495

Jeong, W., Chung, C. K., and Kim, J. S. (2015). Episodic memory in aspects of large-scale brain networks. Front. Hum. Neurosci. 9:454. doi: 10.3389/fnhum. 2015.00454

Kang, N., Peng, H., Yu, Y., Stanton, P. K., Guilarte, T. R., and Kang, J. (2013). Astrocytes release D-serine by a large vesicle. Neuroscience 240, 243-257. doi: 10.1016/j.neuroscience.2013.02.029

Karagiannis, A., Sylantyev, S., Hadjihambi, A., Hosford, P. S., Kasparov, S., and Gourine, A. V. (2015). Hemichannel-mediated release of lactate. J. Cereb. Blood Flow Metab. 36, 1202-1211. doi: 10.1177/0271678X15611912

Kimelberg, H. K. (2005). Astrocytic swelling in cerebral ischemia as a possible cause of injury and target for therapy. Glia 50, 389-397. doi: 10.1002/glia. 20174

Liu, X., Gangoso, E., Yi, C., Jeanson, T., Kandelman, S., Mantz, J., et al. (2016). General anesthetics have differential inhibitory effects on gap junction channels and hemichannels in astrocytes and neurons. Glia 64, 524-536. doi: 10. 1002/glia.22946

Liu, X., Sun, L., Torii, M., and Rakic, P. (2012). Connexin 43 controls the multipolar phase of neuronal migration to the cerebral cortex. Proc. Natl. Acad. Sci. U S A 109, 8280-8285. doi: 10.1073/pnas.1205880109 
Locovei, S., Bao, L., and Dahl, G. (2006a). Pannexin 1 in erythrocytes: function without a gap. Proc. Natl. Acad. Sci. U S A 103, 7655-7659. doi: 10.1073/pnas. 0601037103

Locovei, S., Wang, J., and Dahl, G. (2006b). Activation of pannexin 1 channels by ATP through P2Y receptors and by cytoplasmic calcium. FEBS Lett. 580, 239-244. doi: 10.1016/j.febslet.2005.12.004

Malarkey, E. B., and Parpura, V. (2008). Mechanisms of glutamate release from astrocytes. Neurochem. Int. 52, 142-154. doi: 10.1016/j.neuint.2007.06.005

Montero, T. D., and Orellana, J. A. (2015). Hemichannels: new pathways for gliotransmitter release. Neuroscience 286, 45-59. doi: 10.1016/j.neuroscience. 2014.11.048

Moore, A. R., Zhou, W. L., Sirois, C. L., Belinsky, G. S., Zecevic, N., and Antic, S. D. (2014). Connexin hemichannels contribute to spontaneous electrical activity in the human fetal cortex. Proc. Natl. Acad. Sci. U S A 111, E3919-E3928. doi: 10. 1073/pnas.1405253111

Moraga-Amaro, R., Jerez-Baraona, J. M., Simon, F., and Stehberg, J. (2014). Role of astrocytes in memory and psychiatric disorders. J. Physiol. Paris 108, 240-251. doi: 10.1016/j.jphysparis.2014.08.005

Nadarajah, B., Jones, A. M., Evans, W. H., and Parnavelas, J. G. (1997). Differential expression of connexins during neocortical development and neuronal circuit formation. J. Neurosci. 17, 3096-3111.

Nagy, J. I., Patel, D., Ochalski, P. A., and Stelmack, G. L. (1999). Connexin30 in rodent, cat and human brain: selective expression in gray matter astrocytes, co-localization with connexin43 at gap junctions and late developmental appearance. Neuroscience 88, 447-468. doi: 10.1016/s0306-4522(98) 00191-2

Naus, C. C., Bechberger, J. F., Caveney, S., and Wilson, J. X. (1991). Expression of gap junction genes in astrocytes and C6 glioma cells. Neurosci. Lett. 126, 33-36. doi: 10.1016/0304-3940(91)90364-y

Nedergaard, M. (1994). Direct signaling from astrocytes to neurons in cultures of mammalian brain cells. Science 263, 1768-1771. doi: 10.1126/science.8134839

Neijssen, J., Herberts, C., Drijfhout, J. W., Reits, E., Janssen, L., and Neefjes, J. (2005). Cross-presentation by intercellular peptide transfer through gap junctions. Nature 434, 83-88. doi: 10.1038/nature03290

Orellana, J. A., Avendaño, B. C., and Montero, T. D. (2014). Role of connexins and pannexins in ischemic stroke. Curr. Med. Chem. 21, 2165-2182. doi: 10. 2174/0929867321666131228191714

Orellana, J. A., Froger, N., Ezan, P., Jiang, J. X., Bennett, M. V., Naus, C. C., et al. (2011a). ATP and glutamate released via astroglial connexin 43 hemichannels mediate neuronal death through activation of pannexin 1 hemichannels. J. Neurochem. 118, 826-840. doi: 10.1111/j.1471-4159.2011. 07210.x

Orellana, J. A., Shoji, K. F., Abudara, V., Ezan, P., Amigou, E., Saez, P. J., et al. (2011b). Amyloid $\beta$-induced death in neurons involves glial and neuronal hemichannels. J. Neurosci. 31, 4962-4977. doi: 10.1523/JNEUROSCI.6417-10. 2011

Orellana, J. A., Hernández, D. E., Ezan, P., Velarde, V., Bennett, M. V., Giaume, C., et al. (2010). Hypoxia in high glucose followed by reoxygenation in normal glucose reduces the viability of cortical astrocytes through increased permeability of connexin 43 hemichannels. Glia 58, 329-343. doi: 10.1002/glia. 20926

Orellana, J. A., Moraga-Amaro, R., Díaz-Galarce, R., Rojas, S., Maturana, C. J., Stehberg, J., et al. (2015). Restraint stress increases hemichannel activity in hippocampal glial cells and neurons. Front. Cell. Neurosci. 9:102. doi: 10. 3389/fncel.2015.00102

Orellana, J. A., Sáez, P. J., Cortés-Campos, C., Elizondo, R. J., Shoji, K. F., Contreras-Duarte, S., et al. (2012). Glucose increases intracellular free $\mathrm{Ca}^{2+}$ in tanycytes via ATP released through connexin 43 hemichannels. Glia 60, 53-68. doi: 10.1002/glia.21246

Orellana, J. A., Sáez, P. J., Shoji, K. F., Schalper, K. A., Palacios-Prado, N., Velarde, V., et al. (2009). Modulation of brain hemichannels and gap junction channels by pro-inflammatory agents and their possible role in neurodegeneration. Antioxid. Redox Signal. 11, 369-399. doi: 10.1089/ars.2008.2130

Orellana, J. A., and Stehberg, J. (2014). Hemichannels: new roles in astroglial function. Front. Physiol. 5:193. doi: 10.3389/fphys.2014.00193

Packard, M. G., and Knowlton, B. J. (2002). Learning and memory functions of the basal ganglia. Annu. Rev. Neurosci. 25, 563-593. doi: 10.1146/annurev.neuro. 25.112701.142937
Pan, H. C., Chou, Y. C., and Sun, S. H. (2015). P2X7 R-mediated Ca ${ }^{2+}$ -independent $\mathrm{d}$-serine release via pannexin-1 of the P2X7 R-pannexin-1 complex in astrocytes. Glia 63, 877-893. doi: 10.1002/glia.22790

Panchin, Y., Kelmanson, I., Matz, M., Lukyanov, K., Usman, N., and Lukyanov, S. (2000). A ubiquitous family of putative gap junction molecules. Curr. Biol. 10, R473-R474. doi: 10.1016/s0960-9822(00)00576-5

Pannasch, U., Vargová, L., Reingruber, J., Ezan, P., Holcman, D., Giaume, C., et al. (2011). Astroglial networks scale synaptic activity and plasticity. Proc. Natl. Acad. Sci. U S A 108, 8467-8472. doi: 10.1073/pnas.1016650108

Parpura, V., Basarsky, T. A., Liu, F., Jeftinija, K., Jeftinija, S., and Haydon, P. G. (1994). Glutamate-mediated astrocyte-neuron signalling. Nature 369, 744-747. doi: $10.1038 / 369744 \mathrm{a} 0$

Pellerin, L. (2008). Brain energetics (thought needs food). Curr. Opin. Clin. Nutr. Metab. Care 11, 701-705. doi: 10.1097/MCO.0b013e328312c368

Penuela, S., Harland, L., Simek, J., and Laird, D. W. (2014). Pannexin channels and their links to human disease. Biochem. J. 461, 371-381. doi: 10 1042/BJ20140447

Pini, L., Pievani, M., Bocchetta, M., Altomare, D., Bosco, P., Cavedo, E., et al. (2016). Brain atrophy in Alzheimer's Disease and aging. Ageing Res. Rev. doi: 10.1016/j.arr.2016.01.002 [Epub ahead of print].

Prochnow, N., Abdulazim, A., Kurtenbach, S., Wildförster, V., Dvoriantchikova, G., Hanske, J., et al. (2012). Pannexin1 stabilizes synaptic plasticity and is needed for learning. PLoS One 7:e51767. doi: 10.1371/journal.pone. 0051767

Quesseveur, G., Portal, B., Basile, J. A., Ezan, P., Mathou, A., Halley, H., et al. (2015). Attenuated levels of hippocampal connexin 43 and its phosphorylation correlate with antidepressant- and anxiolytic-like activities in mice. Front. Cell. Neurosci. 9:490. doi: 10.3389/fncel.2015.00490

Rash, J. E., Yasumura, T., Davidson, K. G., Furman, C. S., Dudek, F. E., and Nagy, J. I. (2001). Identification of cells expressing Cx43, Cx30, Cx26, Cx32 and Cx36 in gap junctions of rat brain and spinal cord. Cell Commun. Adhes. 8, 315-320. doi: 10.3109/15419060109080745

Retamal, M. A., Alcayaga, J., Verdugo, C. A., Bultynck, G., Leybaert, L., Saez, P. J., et al. (2014). Opening of pannexin- and connexin-based channels increases the excitability of nodose ganglion sensory neurons. Front. Cell. Neurosci. 8:158. doi: 10.3389/fncel.2014.00158

Retamal, M. A., Cortés, C. J., Reuss, L., Bennett, M. V., and Sáez, J. C. (2006). S-nitrosylation and permeation through connexin 43 hemichannels in astrocytes: induction by oxidant stress and reversal by reducing agents. Proc. Natl. Acad. Sci. U S A 103, 4475-4480. doi: 10.1073/pnas.0511118103

Retamal, M. A., Froger, N., Palacios-Prado, N., Ezan, P., Sáez, P. J., Saez, J. C., et al. (2007). Cx43 hemichannels and gap junction channels in astrocytes are regulated oppositely by proinflammatory cytokines released from activated microglia. J. Neurosci. 27, 13781-13792. doi: 10.1523/jneurosci.2042-07.2007

Revel, J. P., and Karnovsky, M. J. (1967). Hexagonal array of subunits in intercellular junctions of the mouse heart and liver. J. Cell Biol. 33, C7-C12. doi: $10.1083 /$ jcb.33.3.c7

Reyes, E. P., Cerpa, V., Corvalan, L., and Retamal, M. A. (2014). Cxs and Panxhemichannels in peripheral and central chemosensing in mammals. Front. Cell. Neurosci. 8:123. doi: 10.3389/fncel.2014.00123

Roux, L., Madar, A., Lacroix, M. M., Yi, C., Benchenane, K., and Giaume, C. (2015). Astroglial Connexin 43 hemichannels modulate olfactory bulb slow oscillations. J. Neurosci. 35, 15339-15352. doi: 10.1523/JNEUROSCI.0861-15. 2015

Rovegno, M., Soto, P. A., Sáez, P. J., Naus, C. C., Sáez, J. C., and von Bernhardi, R. (2015). Connexin43 hemichannels mediate secondary cellular damage spread from the trauma zone to distal zones in astrocyte monolayers. Glia 63 , 1185-1199. doi: 10.1002/glia.22808

Sahu, G., Sukumaran, S., and Bera, A. K. (2014). Pannexins form gap junctions with electrophysiological and pharmacological properties distinct from connexins. Sci. Rep. 4:4955. doi: 10.1038/srep04955

Santiago, M. F., Veliskova, J., Patel, N. K., Lutz, S. E., Caille, D., Charollais, A., et al. (2011). Targeting pannexin1 improves seizure outcome. PLoS One 6:e25178. doi: 10.1371/journal.pone.0025178

Schalper, K. A., Sanchez, H. A., Lee, S. C., Altenberg, G. A., Nathanson, M. H., and Saez, J. C. (2010). Connexin 43 hemichannels mediate the $\mathrm{Ca}^{2+}$ influx induced by extracellular alkalinization. Am. J. Physiol. Cell Physiol. 299, C1504-C1515. doi: 10.1152/ajpcell.00015.2010 
Sibille, J., Pannasch, U., and Rouach, N. (2014). Astroglial potassium clearance contributes to short-term plasticity of synaptically evoked currents at the tripartite synapse. J. Physiol. 592, 87-102. doi: 10.1113/jphysiol.2013.261735

Simard, M., and Nedergaard, M. (2004). The neurobiology of glia in the context of water and ion homeostasis. Neuroscience 129, 877-896. doi: 10.1016/j. neuroscience.2004.09.053

Song, E. K., Rah, S. Y., Lee, Y. R., Yoo, C. H., Kim, Y. R., Yeom, J. H., et al. (2011). Connexin-43 hemichannels mediate cyclic ADP-ribose generation and its $\mathrm{Ca}^{2+}$-mobilizing activity by $\mathrm{NAD}^{+} /$cyclic ADP-ribose transport. J. Biol. Chem. 286, 44480-44490. doi: 10.1074/jbc.M111.307645

Sosinsky, G. E., Boassa, D., Dermietzel, R., Duffy, H. S., Laird, D. W., Macvicar, B., et al. (2011). Pannexin channels are not gap junction hemichannels. Channels (Austin) 5, 193-197. doi: 10.4161/chan.5.3.15765

Stehberg, J., Moraga-Amaro, R., Salazar, C., Becerra, A., Echeverria, C., Orellana, J. A., et al. (2012). Release of gliotransmitters through astroglial connexin 43 hemichannels is necessary for fear memory consolidation in the basolateral amygdala. FASEB J. 26, 3649-3657. doi: 10.1096/fj.11-198416

Stout, C. E., Costantin, J. L., Naus, C. C., and Charles, A. C. (2002). Intercellular calcium signaling in astrocytes via ATP release through connexin hemichannels. J. Biol. Chem. 277, 10482-10488. doi: 10.1074/jbc.m109902200

Stridh, M. H., Tranberg, M., Weber, S. G., Blomstrand, F., and Sandberg, M. (2008). Stimulated efflux of amino acids and glutathione from cultured hippocampal slices by omission of extracellular calcium: likely involvement of connexin hemichannels. J. Biol. Chem. 283, 10347-10356. doi: 10.1074/jbc. M704153200

Szatkowski, M., Barbour, B., and Attwell, D. (1990). Non-vesicular release of glutamate from glial cells by reversed electrogenic glutamate uptake. Nature 348, 443-446. doi: 10.1038/348443a0

Takano, T., Tian, G. F., Peng, W., Lou, N., Libionka, W., Han, X., et al. (2006). Astrocyte-mediated control of cerebral blood flow. Nat. Neurosci. 9, 260-267. doi: $10.1038 / \mathrm{nn} 1623$

Thompson, R. J., Zhou, N., and MacVicar, B. A. (2006). Ischemia opens neuronal gap junction hemichannels. Science 312, 924-927. doi: 10.1126/science.1126241

Valiunas, V., Polosina, Y. Y., Miller, H., Potapova, I. A., Valiuniene, L., Doronin, S., et al. (2005). Connexin-specific cell-to-cell transfer of short interfering RNA by gap junctions. J. Physiol. 568, 459-468. doi: 10.1113/jphysiol.2005. 090985

Weilinger, N. L., Tang, P. L., and Thompson, R. J. (2012). Anoxia-induced NMDA receptor activation opens pannexin channels via Src family kinases. J. Neurosci. 32, 12579-12588. doi: 10.1523/JNEUROSCI.1267-12.2012

Wenker, I. C., Sobrinho, C. R., Takakura, A. C., Moreira, T. S., and Mulkey, D. K. (2012). Regulation of ventral surface $\mathrm{CO}_{2} / \mathrm{H}^{+}$-sensitive neurons by purinergic signalling. J. Physiol. 590, 2137-2150. doi: 10.1113/jphysiol.2012. 229666

Wilhelm, F., and Hirrlinger, J. (2012). Multifunctional roles of $\mathrm{NAD}^{+}$and NADH in astrocytes. Neurochem. Res. 37, 2317-2325. doi: 10.1007/s11064-012-0760-y

Winship, I. R., Plaa, N., and Murphy, T. H. (2007). Rapid astrocyte calcium signals correlate with neuronal activity and onset of the hemodynamic response in vivo. J. Neurosci. 27, 6268-6272. doi: 10.1523/jneurosci.4801-06.2007

Yang, J., Ruchti, E., Petit, J. M., Jourdain, P., Grenningloh, G., Allaman, I., et al. (2014). Lactate promotes plasticity gene expression by potentiating NMDA signaling in neurons. Proc. Natl. Acad. Sci. U S A 111, 12228-12233. doi: 10. 1073/pnas.1322912111

Ye, Z. C., Wyeth, M. S., Baltan-Tekkok, S., and Ransom, B. R. (2003). Functional hemichannels in astrocytes: a novel mechanism of glutamate release. J. Neurosci. 23, 3588-3596.

Zappalà, A., Cicero, D., Serapide, M. F., Paz, C., Catania, M. V., Falchi, M., et al. (2006). Expression of pannexin1 in the CNS of adult mouse: cellular localization and effect of 4-aminopyridine-induced seizures. Neuroscience 141, 167-178. doi: 10.1016/j.neuroscience.2006.03.053

Zgaljardic, D. J., Borod, J. C., Foldi, N. S., and Mattis, P. (2003). A review of the cognitive and behavioral sequelae of Parkinson's disease: relationship to frontostriatal circuitry. Cogn. Behav. Neurol. 16, 193-210. doi: 10. 1097/00146965-200312000-00001

Zhang, J. M., Wang, H. K., Ye, C. Q., Ge, W., Chen, Y., Jiang, Z. L., et al. (2003). ATP released by astrocytes mediates glutamatergic activity-dependent heterosynaptic suppression. Neuron 40, 971-982. doi: 10.1016/s08966273(03)00717-7

Zoidl, G., Petrasch-Parwez, E., Ray, A., Meier, C., Bunse, S., Habbes, H. W., et al. (2007). Localization of the pannexin1 protein at postsynaptic sites in the cerebral cortex and hippocampus. Neuroscience 146, 9-16. doi: 10.1016/j. neuroscience.2007.01.061

Conflict of Interest Statement: The authors declare that the research was conducted in the absence of any commercial or financial relationships that could be construed as a potential conflict of interest.

Copyright (C) 2016 Orellana, Retamal, Moraga-Amaro and Stehberg. This is an openaccess article distributed under the terms of the Creative Commons Attribution License (CC BY). The use, distribution and reproduction in other forums is permitted, provided the original author(s) or licensor are credited and that the original publication in this journal is cited, in accordance with accepted academic practice. No use, distribution or reproduction is permitted which does not comply with these terms. 